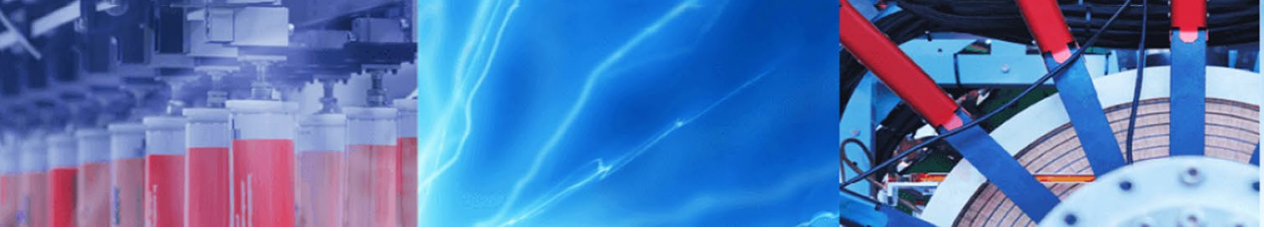

Research Article

\title{
Optimization of end milling on Al-SiC-fly ash metal matrix composite using Topsis and fuzzy logic
}

\author{
N. Tamiloli ${ }^{1}$ J. Venkatesan ${ }^{2}$-G. Murali ${ }^{1}$.Shyam Prasad Kodali ${ }^{1} \cdot$ T. Sampath Kumar $^{3}$ - M. P. Arunkumar ${ }^{1}$
}

C The Author(s) 2019 OPEN

\begin{abstract}
Metal matrix composites are extensively used in aerospace, automobile and other engineering applications as an alternative to a wide range of elements. High strength-weight ratio, durability and high corrosion resistance are benefits of metal matrix composites. The study that exhibits adopts optimal cutting parameters (speed, feed and depth of cut). The initial study is to explore end milling process of alumina (AA6082 with $\mathrm{SiC} 3 \%$ and fly ash $2 \%$ ) molted metal matrix composite. The technique for order preference by similarity to ideal solution and fuzzy logic for optimizing the cutting parameter values has been utilized in the MMC. The response surface methodology is being used to develop the numerical model between output responses and machining parameters. The second-order regression models are studied through analysis of variance. The experimental investigation exhibits that feed rate is the important factor on response variables.
\end{abstract}

Keywords Milling $\cdot$ Alumina $\cdot$ Optimum $\cdot$ Machining $\cdot$ Composites $\cdot$ Fuzzy logic

\section{Introduction}

Metal matrix composites (MMCs) have a rare mechanical property. Reinforced aluminum MMC has a notable design property. These materials have been recognized as hardto-machine materials, due to their durability and abrasive nature of support components like silicon carbide particles [1]. The MMCs are most generally used in aviation and automotive industries [2]. End milling is one of the primary machining activities used in modern industries due to its ability to produce geometric surfaces, accuracy and surface finish. The surface roughness (SR) of the component highly depends on the exclusive cutting parameters. SR is the major parameter, used for assurance and the estimation of the quality characteristics. SR and material removal rate (MRR) are the measures of the quality of a product and have a significant impact on the product cost.

Although destruction has been used in this article, technique for order preference by similarity to ideal solution
(Topsis) presented by Hwang and Yoon [3] has been utilized for evaluation of the alternatives. Vinodh et al. [4] have built up a tool with integrated fuzzy, analytical hierarchy process (AHP) and Topsis for doing execution assessment and distinguishing the best strategy for the reuse of plastics. Nayak and Mahapatra [5] utilized AHP with Topsis method for the optimization of various responses like MRR, surface finish and kerf angle. Dewangan et al. [6] examined the impact of different electro-discharge machining (EDM) parameters on the distinctive parts of surface integrity. A response surface methodology (RSM)based design of experiment was treated in their research. Awasthi et al. [7] proposed a crossbreed approach in the light of the service quality model and fuzzy logic (FI)Topsis for assessing the administration nature of urban transportation frame works. Fuzzy with Topsis is used to resolve the relative weights of decision criteria [8]. A fuzzyTopsis-based system for appraisal and decision of vertical computer numerical control machining centers for an

\footnotetext{
$\triangle$ N. Tamiloli, tamiloligg@gmail.com | 1 Department of Mechanical Engineering, KL University, Vaddeswaram, AP, India. ${ }^{2}$ Department of Mechanical Engineering, Sri Venkateswara College of Engineering, Sriperumbudur, Tamil Nadu, India. ${ }^{3}$ School of Mechanical Engineering, VIT University, Vellore, Tamil Nadu, India.
} 
assembling unit is studied by Onut et al. [9]. Yurdalul and Lc [10] evaluate the advantages of utilizing fuzzy numbers instead of crisp numbers in a Topsis method based on instrument choice model. The conclusion was that fuzzy numbers should be preferred instead of crisp in the decision-making issues.

Sidhu et al. [11] investigated the effect of EDM process parameters on the surface properties of variant Al/ $\mathrm{SiC}$ composites. Their result shows that microhardness of the machined surface is directly proportional to the concentration of reinforced ( $\mathrm{SiC}$ ) particulates. Gadakh [12] applied Topsis for taking care of various criteria enhancement issues in the wire-EDM procedure. Yurdakul and Cogun [13] have proposed a determination strategy for non-traditional machining processes (NTMPs) in the light of a gathering of AHP and Topsis techniques. Temucin et al. [14] built up a fuzzy-based choice help for demonstrating NTMPs choice through application of Topsis and fuzzyTopsis strategies. Shivakoti et al. [15] used the triangular fuzzy member for ascertain the weight performance criteria, and fuzzy-Topsis. Kumar et al. [16] applied the Taguchi and Topsis techniques in the EDM machining process with conventional electrodes on $\mathrm{M} 2$ tool steel with aluminum power and without aluminum powder.

Sidhu et al. [17] studied the surface modification of three different types of metal matrix composite using powder mixed electrical discharge machining process and reported that microhardness increased primarily with increase in the density of reinforced particles in the matrix. Shunmugesh and Paneerselvam [18] studied the drilling parameter with carbon fiber reinforced polymer. The result shows that multi-objective technique has good agreement with Topsis technique. Arif Gok [19] studied the SR expectation dependent on the cutting parameters in turning operation. Tamiloli et al. [20] dealt with improvement in cutting parameters for end milling process dependent on gray-fuzzy logic for SR and MRR. The statistical methods of signal-to-noise ratio and analysis of variance are applied in their investigation. Sidhu and Yazdani [21] used lexicographic goal programming for investigating the better EDM machining parameters to optimize conflicting objectives such as induced residual stresses on the machined surface, tool wear rate and material removal rate. Makadia [22] studied the machining parameters and output response (SR). The outcomes revealed the feed rate is the main influencing factor of the machining parameter.

Sidhu [23] reports the optimal process conditions for machining of three different types of MMC's: $65 \mathrm{vol} \% \mathrm{SiC} /$ A356.2; 10 vol\% SiC-5 vol\% quartz/Al; and 30 vol\% SiC/ A359 using powder mixed electric discharge machining process. MRR, TWR, SR and surface integrity were identified. The four responses were then collectively optimized using Topsis, and optimal process conditions were identified for each type of MMC. Roy and Dutta [24] studied about the multi-objective optimization of electrical discharge machining using integrated fuzzy AHP and fuzzyTopsis method. A fuzzy-Topsis method was used [25] to optimize multiple responses, viz. SR, MRR and tool wear rate, in EDM based on various process parameters. Recast layer thickness and SR were optimized [26] using Taguchibased fuzzy logic technique. This technique significantly improved multiple responses in WEDM. Topsis is a wellknown application in many areas [27-31] and given a choice network and a basic leadership strategy.

Topsis finds an ideal choice elective that is at the closest partition to the positive ideal solution (PIS) and most remote division to the negative ideal solution (NIS). PIS is an ideal arrangement wail, and NIS is the most perceptibly horrendous game plan that is not of any interest. Based on the multi-regression analysis, a suitable mathematical model of the responses has been established. The prime objective of this research is to minimize the surface roughness and normal cutting force simultaneously. Thus, this case of an inconsistent condition requires multi-objective optimization tool for an optimum solution. In the second phase of analysis, the multi-optimization techniques such as technique for order preference by similarity to ideal solution and fuzzy logic have been adopted to optimal solution.

\section{Materials and methods}

The stir casting method is used to reinforce silicon, fly ash and aluminum alloy 6082T6. The chemical composition of AA6082T6, silicon carbide and fly ash is shown in Table 1. Initially, the silicon and sieved fly ash (50-75 $\mu \mathrm{m})$ are preheated at $650{ }^{\circ} \mathrm{C}$. Using the electrical furnace,
Table 1 Chemical composition of aluminum, silicon carbide and fly ash

\begin{tabular}{lc}
\hline Materials & Chemical compositions \\
\hline AA6082T6 & $\mathrm{Si}(0.7-1 \%), \mathrm{Fe}(0.5 \%), \mathrm{Cu}(0.1 \%), \mathrm{Mn}(0.4-1 \%), \mathrm{Mg}(0.6-1.20 \%), \mathrm{Cr}$ \\
& $(0.25 \%), \mathrm{Zn}(0.20 \%), \mathrm{Ti}(0.1 \%)$ and aluminum (remaining) \\
Silicon carbide & $\mathrm{Sic}(98.7 \%), \mathrm{Si}(0.3 \%), \mathrm{SiO}_{2}(0.4 \%), \mathrm{Fe}(0.08 \%), \mathrm{Al}(0.1 \%)$ and $\mathrm{C}(0.3 \%)$ \\
Fly ash & $\mathrm{SiO}_{2}(52.78 \%), \mathrm{Al}_{2} \mathrm{O}_{3}(24.48 \%), \mathrm{Fe}_{2} \mathrm{O}_{3}(6.25 \%), \mathrm{CaO}(11.08 \%), \mathrm{MgO}$ \\
& $(2.58 \%), \mathrm{SO}_{3}(1.31 \%)$ and loss of ignition $1.3 \%$ by weight \\
\hline
\end{tabular}


Fig. 1 Microstructure (aluminum $95 \%+$ Sic $3 \%+$ fly ash $2 \%)$

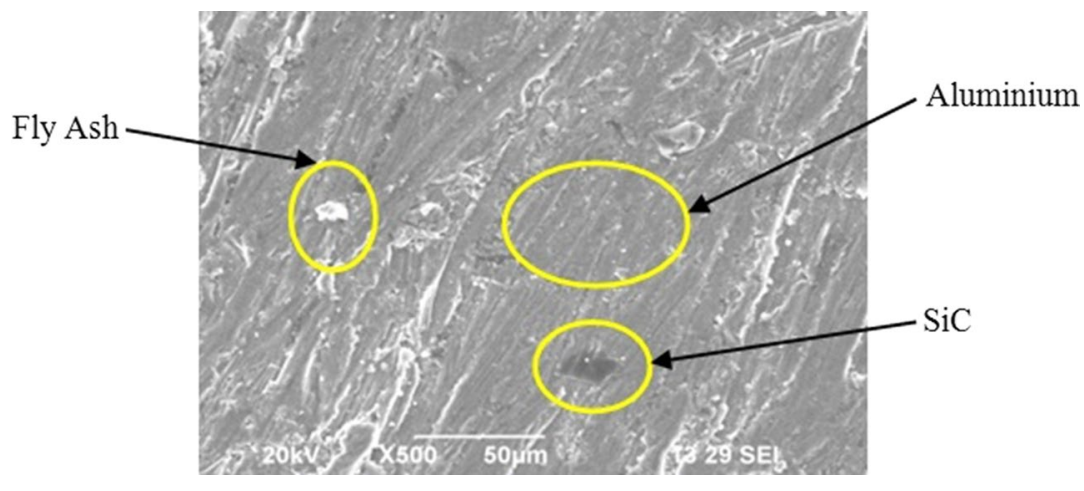

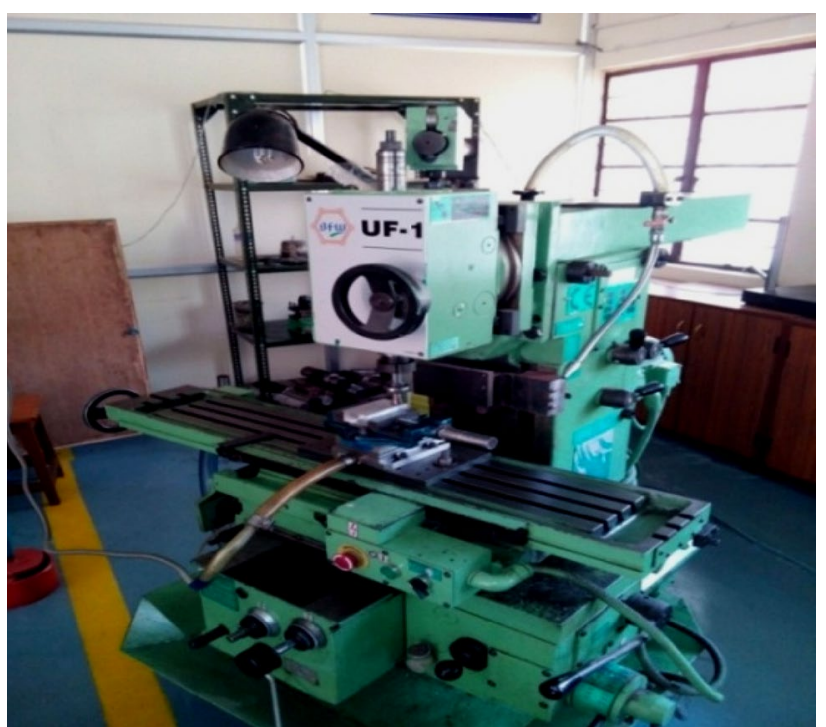

Fig. 3 Knee-type vertical milling machine

Table 3 Process variables with their limits

\begin{tabular}{lllll}
\hline Parameters & Unit & Level 1 & Level 2 & Level 3 \\
\hline Spindle speed (A) & $\mathrm{rpm}$ & 500 & 710 & 1000 \\
Feed (B) & $\mathrm{mm} / \mathrm{min}$ & 40 & 63 & 100 \\
Depth of cut (C) & $\mathrm{mm}$ & 0.5 & 0.75 & 1.0 \\
\hline
\end{tabular}

\subsection{Process variables with their limits}

The machining was carried out on a knee-type milling machine (model: UF-1) as shown in Fig. 3. The work material selected for the study was aluminum $95 \%+\mathrm{SiC} 3 \%+$ fly ash $2 \%$. Based on the Taguchi, orthogonal array (OA) was considered $L 27$ experiments required for the determination of the optimal level. Speed (A), feed rate (B) and depth of cut (DOC) (C) as machining parameters and surface roughness and normal force were selected as a process performance. In Table 3, the levels of machining parameters are shown. 
Table 4 Results of surface roughness and cutting force using L27 orthogonal array

\begin{tabular}{|c|c|c|c|c|c|}
\hline S. no. & $\begin{array}{l}\text { Speed } \\
\text { (rpm) }\end{array}$ & $\begin{array}{l}\text { Feed }(\mathrm{mm} / \\
\mathrm{min})\end{array}$ & Doc (mm) & $\mathrm{SR} R_{\mathrm{a}}(\mu \mathrm{m})$ & $F_{\mathrm{z}}(\mathrm{N})$ \\
\hline 1 & 500 & 40 & 0.5 & 4.416 & 144.000 \\
\hline 2 & 500 & 40 & 0.75 & 4.525 & 144.149 \\
\hline 3 & 500 & 40 & 1 & 4.108 & 125.766 \\
\hline 4 & 500 & 63 & 0.5 & 5.301 & 182.156 \\
\hline 5 & 500 & 63 & 0.75 & 4.830 & 160.300 \\
\hline 6 & 500 & 63 & 1 & 4.467 & 145.390 \\
\hline 7 & 500 & 100 & 0.5 & 5.878 & 213.725 \\
\hline 8 & 500 & 100 & 0.75 & 5.461 & 195.341 \\
\hline 9 & 500 & 100 & 1 & 5.831 & 156.200 \\
\hline 10 & 710 & 40 & 0.5 & 5.548 & 169.442 \\
\hline 11 & 710 & 40 & 0.75 & 4.908 & 150.200 \\
\hline 12 & 710 & 40 & 1 & 4.714 & 132.675 \\
\hline 13 & 710 & 63 & 0.5 & 5.907 & 189.065 \\
\hline 14 & 710 & 63 & 0.75 & 5.490 & 170.682 \\
\hline 15 & 710 & 63 & 1 & 5.639 & 170.700 \\
\hline 16 & 710 & 100 & 0.5 & 6.484 & 277.200 \\
\hline 17 & 710 & 100 & 0.75 & 6.067 & 202.250 \\
\hline 18 & 710 & 100 & 1 & 5.650 & 183.867 \\
\hline 19 & 1000 & 40 & 0.5 & 6.385 & 178.983 \\
\hline 20 & 1000 & 40 & 0.75 & 5.968 & 160.599 \\
\hline 21 & 1000 & 40 & 1 & 6.610 & 164.100 \\
\hline 22 & 1000 & 63 & 0.5 & 7.643 & 180.100 \\
\hline 23 & 1000 & 63 & 0.75 & 6.327 & 180.223 \\
\hline 24 & 1000 & 63 & 1 & 5.910 & 161.84 \\
\hline 25 & 1000 & 100 & 0.5 & 7.321 & 230.175 \\
\hline 26 & 1000 & 100 & 0.75 & 6.904 & 197.600 \\
\hline 27 & 1000 & 100 & 1 & 6.487 & 193.408 \\
\hline
\end{tabular}

\subsection{Evaluation of surface roughness (SR) $\left(R_{\mathrm{a}}\right)$ and cutting force $\left(F_{z}\right)$}

SR measurement was taken by portable stylus-type profilometer. The machining was carried out under dry cutting condition with tungsten carbide insert (single side). The arithmetic average values $R_{\mathrm{a}}(\mu \mathrm{m})$ were measured with the help of a surface roughness tester (Mitutoyo model SJ-210), and normal feed force $\left(F_{\mathrm{z}}\right)(N)$ was carried out with help of Kistler dynamometer. The L27 (full factorial) experimental values are shown in Table 4.

\subsection{Topsis steps}

The recommended optimization techniques of Topsis and $\mathrm{Fl}$ procedure are shown in Fig. 4. The Topsis steps are summarized in Fig. 5. Normalized decision matrix, weighted normalized values, separation measures, average, fuzzy reasoning grade (FRG) and ranks are shown in Table 5.

\subsection{Fuzzy rule-based modeling}

During this analysis, the multi-objective responses were changed to single objective optimization utilizing the Topsis technique. The uncertainties in the output were condensed further by Fl. The criteria acknowledged as the best executions with machining aluminum composites need aid for lower surface roughness and normal feed force.

Utilizing the Topsis technique, the original sequence data were converted into normalized decision matrix. After that all the machining parameters are manipulated. A more significant value of the average was indicative of the good performance characteristic equal to one. The parametric condition was corresponding to the highest cutting force and SR. However, there is a tendency of a certain level of a particular degree about the controversial matter to bring about shortage.

Uncertainties emerged mainly due to the imprecision and absence of the majority of the data. The Fl approach appeared to offer a compelling result for controlling these averages. As a result, fuzzy thinking about various execution qualities was formed and suggest to the fuzzy thinking evaluation. The steps in the Fl approach include fuzzification of input data, principle induction for more defuzzification procedure [22].

The fuzzy algorithm for deciding the ideal level about machining parameters and the steps included are summarized as follows.

- The extended parameters may be determined, and a suitable orthogonal show adjusted for leading examinations.

- Responses such as SR and $F_{z}$ were considered for each trial. These responses were initially normalized during data preprocessing. Following this, normalized decision matrix weighted normalized values and separation measures, average and FRG determined are listed in Table 3. The input parameters and output values were normalized with help of Topsis.

The triangular membership function and fuzzy rule were established to fuzzify the speed $\xi(k)$ of every response. Three fuzzy subsets were assigned to the surface roughness and cutting force using the membership function. IF-THEN rule statement was used for formulating conditional statements. It has three machining parameters (speed, feed and DOC) $\xi_{1}, \xi_{i}(k) \xi_{2}, \xi_{3}$, and one multiresponse output $\eta$; these are represented as follows:

Rule 1 : if $\xi_{1}$ is $A_{11}, \xi_{2}$ is $A_{12}$ and $\xi_{3}$ is $A_{1 n}$, then $\eta$ is $D_{1}$, else 


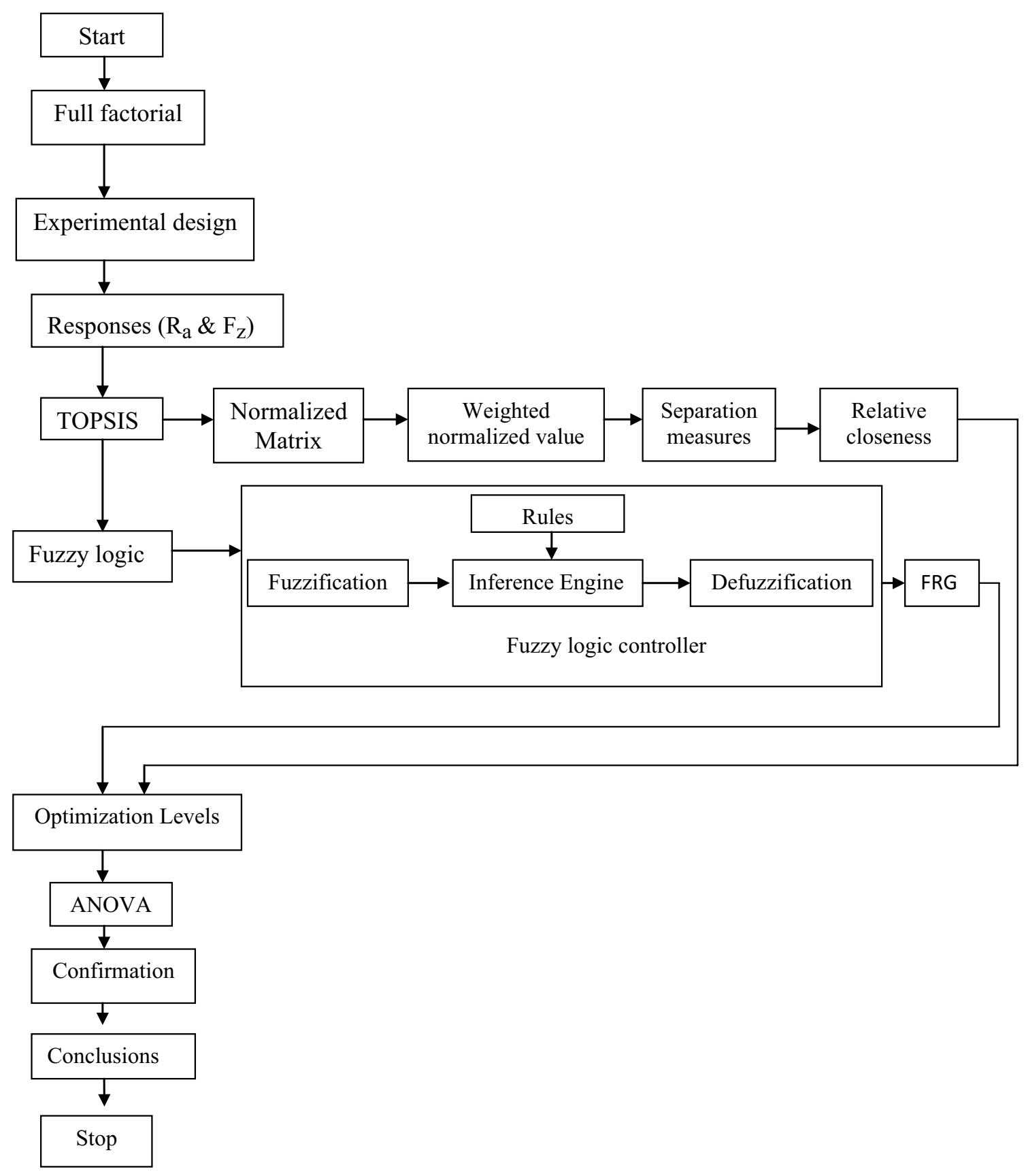

Fig. 4 Flowchart of the research

Nine fuzzy subsets were utilized for the multi-reactions output $\eta$. The scope of each fuzzy subset is exhibited in Table 5. In light of the exploratory arrangement, fuzzy rules were produced by the concurrence concept that a substantial parameter would be a superior procedure reaction.

- Fuzzy multi-reactions output (normal) $\mu D 0(\eta)$ is figured with the maximum and minimum interface tasks. The inferential outcome in a fuzzy set with a participation work for the multi-reaction output $\eta$ can be expressed as:

$$
\begin{aligned}
& \mu D_{0}(\eta)=\left(\mu A _ { 1 1 } ( \xi _ { 1 } ) \wedge \left(\mu A _ { 1 2 } ( \xi _ { 2 } ) \wedge \left(\mu A_{13}\left(\xi_{3}\right)\right.\right.\right. \\
& \wedge\left(\mu D _ { 1 } ( \eta ) \vee \left(\mu A _ { 2 1 } ( \xi _ { 1 } ) \wedge \left(\mu A _ { 2 2 } ( \xi _ { 2 } ) \wedge \left(\mu A_{23}\left(\xi_{3}\right)\right.\right.\right.\right. \\
& \wedge \mu D_{2}(\eta) \vee\left(\mu A _ { 3 1 } ( \xi _ { 1 } ) \wedge \left(\mu A _ { 3 2 } ( \xi _ { 2 } ) \wedge \left(\mu A_{33}\left(\xi_{3}\right) \wedge \mu D_{3}(\eta)\right.\right.\right.
\end{aligned}
$$

where $\wedge$ and $\wedge$ are the mini-max operations, respectively. 


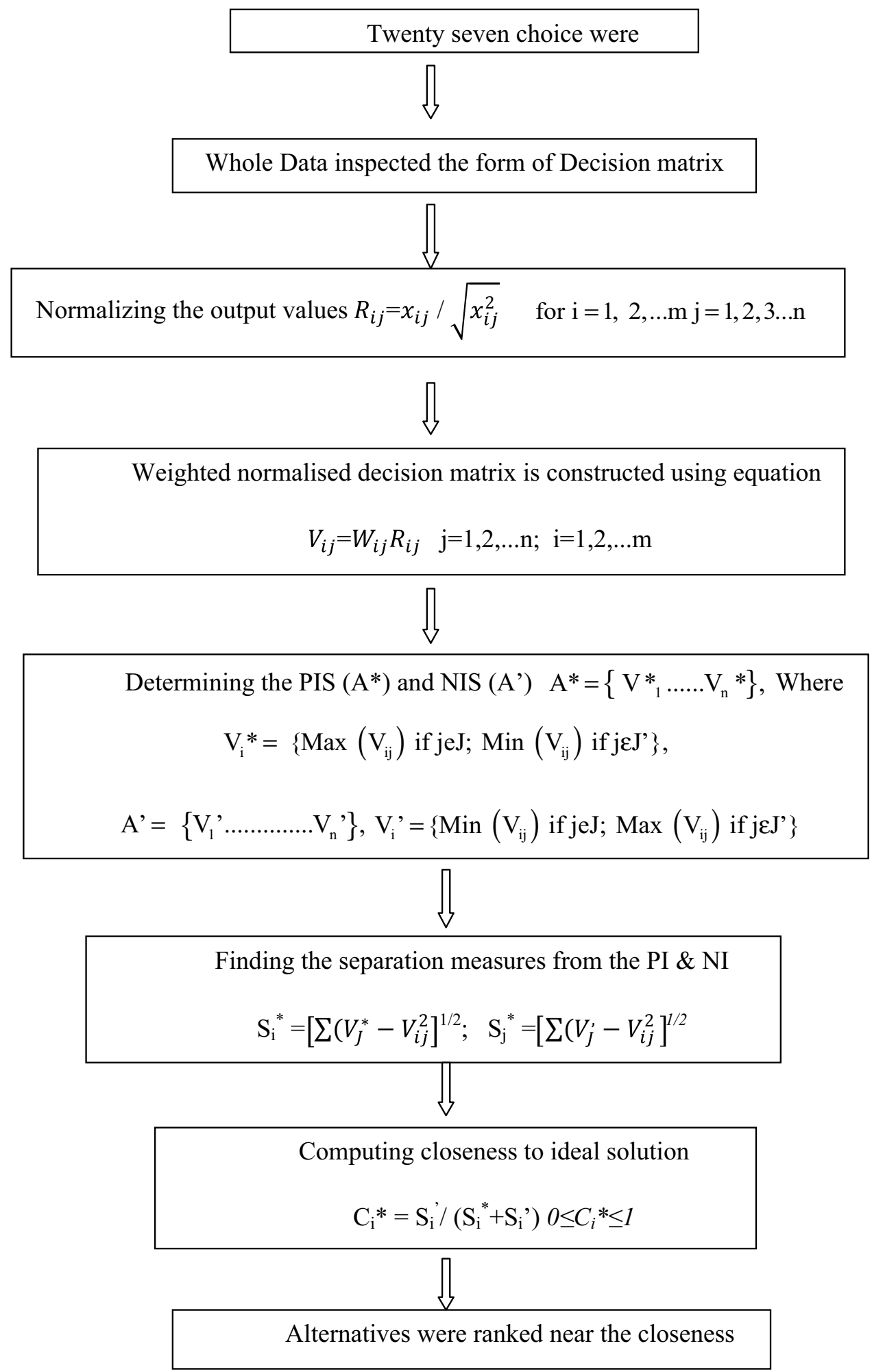


Table 5 Normalized decision matrix, weighted normalized values, separation measures, average, fuzzy reasoning grade (FRG) and rank

\begin{tabular}{|c|c|c|c|c|c|c|c|c|c|c|}
\hline \multirow[t]{2}{*}{ S. no. } & \multicolumn{2}{|c|}{$\begin{array}{l}\text { Normalized deci- } \\
\text { sion matrix }\end{array}$} & \multicolumn{2}{|c|}{$\begin{array}{l}\text { Weighted nor- } \\
\text { malized values }\end{array}$} & \multicolumn{2}{|c|}{$\begin{array}{l}\text { Separation } \\
\text { measures }\end{array}$} & \multirow[t]{2}{*}{ Average } & \multirow[t]{2}{*}{ Rank } & \multirow[t]{2}{*}{ FRG } & \multirow[t]{2}{*}{ Rank } \\
\hline & $R_{\mathrm{a}}$ & $F_{\mathrm{z}}$ & $R_{\mathrm{a}}$ & $F_{\mathrm{z}}$ & $R_{\mathrm{a}}$ & $F_{\mathrm{z}}$ & & & & \\
\hline 1 & 0.1465 & 0.1555 & 0.073 & 0.078 & 0.011 & 0.090 & 0.890 & 3 & 0.888 & 2 \\
\hline 2 & 0.1502 & 0.1556 & 0.075 & 0.078 & 0.012 & 0.089 & 0.880 & 4 & 0.878 & 3 \\
\hline 3 & 0.1363 & 0.1358 & 0.068 & 0.068 & 0.000 & 0.101 & 1.000 & 1 & 0.950 & 1 \\
\hline 4 & 0.1759 & 0.1967 & 0.088 & 0.098 & 0.036 & 0.064 & 0.639 & 14 & 0.629 & 14 \\
\hline 5 & 0.1603 & 0.1731 & 0.080 & 0.087 & 0.022 & 0.078 & 0.780 & 7 & 0.781 & 7 \\
\hline 6 & 0.1482 & 0.1570 & 0.074 & 0.078 & 0.012 & 0.089 & 0.879 & 5 & 0.875 & 5 \\
\hline 7 & 0.1951 & 0.2308 & 0.098 & 0115 & 0.056 & 0.045 & 0.447 & 24 & 0.437 & 25 \\
\hline 8 & 0.1812 & 0.2109 & 0.091 & 0.105 & 0.044 & 0.057 & 0.566 & 17 & 0.572 & 19 \\
\hline 9 & 0.1935 & 0.1686 & 0.097 & 0.084 & 0.033 & 0.072 & 0.686 & 8 & 0.750 & 8 \\
\hline 10 & 0.1841 & 0.1829 & 0.092 & 0.091 & 0.034 & 0.068 & 0.669 & 10 & 0.680 & 10 \\
\hline 11 & 0.1628 & 0.1622 & 0.081 & 0.081 & 0.019 & 0.082 & 0.815 & 6 & 0.878 & 3 \\
\hline 12 & 0.1564 & 0.1432 & 0.078 & 0.072 & 0.011 & 0.092 & 0.896 & 2 & 0.875 & 5 \\
\hline 13 & 0.1960 & 0.2041 & 0.098 & 0.102 & 0.045 & 0.056 & 0.551 & 18 & 0.583 & 17 \\
\hline 14 & 0.1822 & 0.1843 & 0.091 & 0.092 & 0.033 & 0.068 & 0.670 & 9 & 0.657 & 11 \\
\hline 15 & 0.1871 & 0.1843 & 0.094 & 0.092 & 0.030 & 0.066 & 0.654 & 13 & 0.719 & 9 \\
\hline 16 & 0.2152 & 0.2993 & 0.108 & 0.150 & 0.091 & 0.019 & 0.175 & 27 & 0.333 & 27 \\
\hline 17 & 0.2013 & 0.2184 & 0.101 & 0.109 & 0.053 & 0.048 & 0.478 & 22 & 0.469 & 24 \\
\hline 18 & 0.1875 & 0.1985 & 0.094 & 0.099 & 0.040 & 0.060 & 0.598 & 15 & 0.572 & 19 \\
\hline 19 & 0.2119 & 0.1932 & 0.106 & 0.097 & 0.047 & 0.057 & 0.546 & 20 & 0.583 & 17 \\
\hline 20 & 0.1980 & 0.1734 & 0.099 & 0.087 & 0.036 & 0.069 & 0.656 & 12 & 0.643 & 12 \\
\hline 21 & 0.2193 & 0.1772 & 0.110 & 0.089 & 0.046 & 0.063 & 0.578 & 16 & 0.625 & 15 \\
\hline 22 & 0.2536 & 0.1945 & 0.127 & 0.097 & 0.066 & 0.052 & 0.444 & 25 & 0.513 & 22 \\
\hline 23 & 0.2100 & 0.1946 & 0.105 & 0.097 & 0.047 & 0.057 & 0.546 & 19 & 0.531 & 21 \\
\hline 24 & 0.1961 & 0.1747 & 0.098 & 0.087 & 0.036 & 0.069 & 0.658 & 11 & 0.631 & 13 \\
\hline 25 & 0.2429 & 0.2485 & 0.121 & 0.124 & 0.078 & 0.026 & 0.251 & 26 & 0.354 & 26 \\
\hline 26 & 0.2291 & 0.1918 & 0.115 & 0.096 & 0.054 & 0.055 & 0.504 & 21 & 0.593 & 16 \\
\hline 27 & 0.2153 & 0.2088 & 0.108 & 0.104 & 0.054 & 0.049 & 0.477 & 23 & 0.500 & 23 \\
\hline
\end{tabular}

- Fuzzy reasoning grade $\eta_{0}$ is considered from fuzzy multiresponses output $\mu D_{0}(\eta)$ with the accompanying equation:

$$
\eta_{0}=\Sigma y \mu D_{0}(y) / \Sigma \mu D_{0}(y)
$$

- Optimum level of parameters was resolved for the utilization of the data found in the response table and after that assessed.

- The results were obtained based on the confirmation test carried out for the optimum level of machining parameters.

\section{Methodology for fuzzy logic}

- Selection of the input parameters and their levels.

- To perform the experiments, values utilize a $L_{27}$ design.
- Calculation of SR and $F_{z^{\prime}} \xi_{\mathrm{i}}(k)$ for every response by utilizing Eqs. (1), (2) was utilized for the generation of the overall fuzzy reasoning grade $\gamma_{i}$.

- Fuzzification of the $S R$ and $F_{z}$ was obtained from every response and fuzzification of the general FRG by utilizing the membership function. Likewise, the rules in a linguistic form relating to $S R, F_{z}$ and overall FRG were built up.

- Calculation of the fuzzy multi-response output $\mu D_{0}(\eta)$ utilizing the max-min interface operation (Eq. 3) was trailed by employment of centroid defuzzification and by computation of a fuzzy reasoning grade $\eta_{0}$.

- Selection of the optimum combination of parameters found in the response table and the graph. Interaction effects were determined with help of ANOVA for finding the contribution of each parameter.

- Finally, a confirmation test was conducted in the outcomes. 
Fig. 6 Optimal level of surface roughness

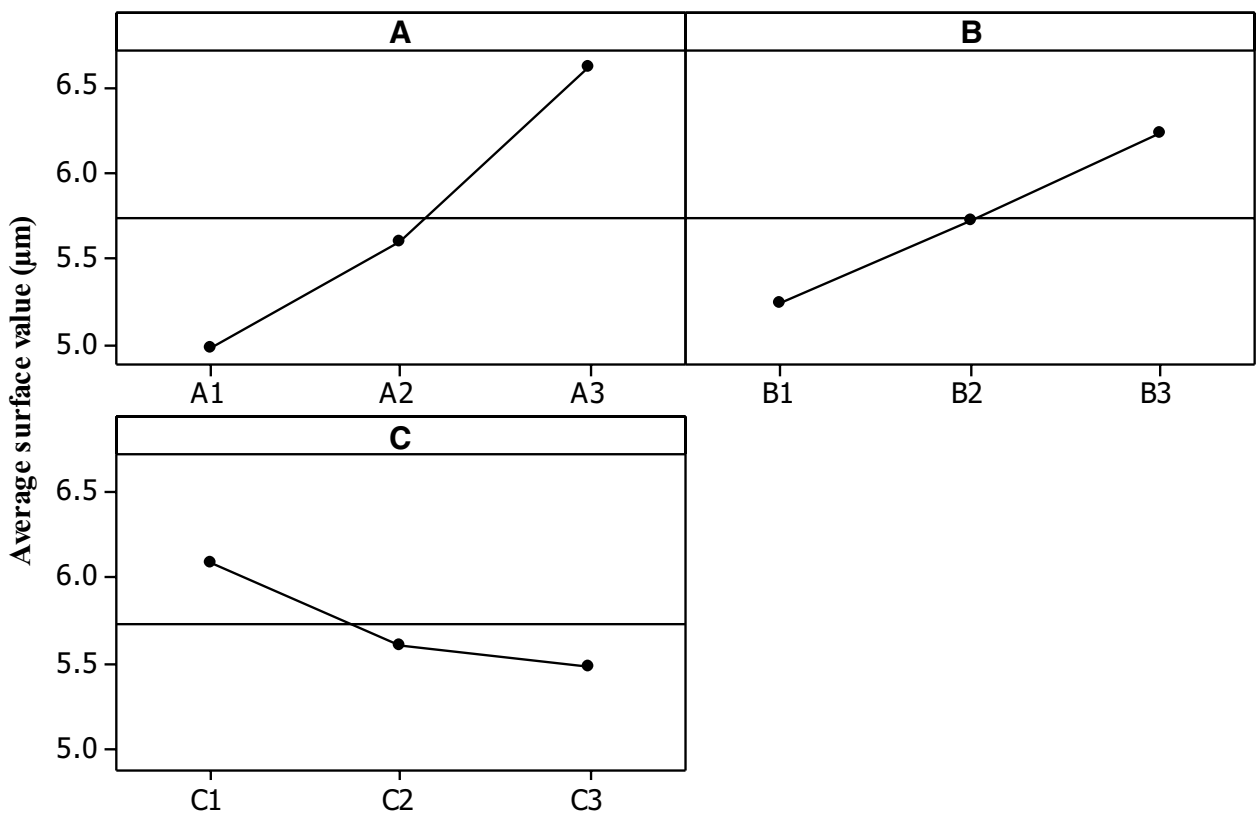

Table 6 Average values of surface roughness

\begin{tabular}{llll}
\hline S. no & L1 & L2 & L3 \\
\hline 1 & 4.980 & 5.601 & $\mathbf{6 . 6 1 7}$ \\
2 & 5.242 & 5.724 & $\mathbf{6 . 2 3 1}$ \\
3 & $\mathbf{6 . 0 9 8}$ & 5.609 & 5.491 \\
\hline
\end{tabular}

Table 7 ANOVA for surface roughness

\begin{tabular}{lcrlll}
\hline Parameters & DOF & \multicolumn{1}{l}{ SS } & MSS & \multicolumn{1}{l}{$F_{\text {cal }}$} & \% contribution \\
\hline A & 2 & 12.302 & 6.151 & 41.631 & 59.083 \\
B & 2 & 4.403 & 2.201 & 14.899 & 21.145 \\
C & 2 & 1.867 & 0.933 & 6.318 & 8.967 \\
AB & 4 & 0.555 & 0.139 & 0.939 & 2.664 \\
BC & 4 & 0.328 & 0.082 & 0.555 & 1.576 \\
AC & 4 & 0.185 & 0.046 & 0.313 & 0.889 \\
Error & 8 & 1.182 & 0.148 & & 5.677 \\
Total & 26 & 20.821 & 0.801 & & 100 \\
\hline
\end{tabular}

\section{Results and discussion}

\subsection{Effect of surface roughness}

Figure 6 shows the main effect plots for the surface roughness. It is clear from the graph in Fig. 6 that with the increase in cutting speed, the surface roughness value first decreases to a substantial amount and then increases. As cutting speed increases, it minimizes the built-up edge development. In addition to this high-speed machining, more heat is produced which raises the temperature in the shear zone and makes the material removal easier for the cutting tool and ultimately decreases surface roughness [32]. From the graph, with the cutting speed of $500 \mathrm{rpm}$, the surface roughness starts increasing up to $1000 \mathrm{rpm}$; it might be due to some chatters or material flow on side of sample [33].

Figure 6 shows the optimal level as A3-B3-C1 (speed $1000 \mathrm{rpm}$, feed $100 \mathrm{~mm} / \mathrm{min}$ and DOC $1 \mathrm{~mm}$ ) in a single response. Huang et al. [34] and Das et al. [35] found that the surface roughness increases as the feed rate increases; it produces the thrust forces which act on the surface and also produces vibrations which ultimately increase surface roughness. This results in an increase in the values of surface roughness. As depth of cut increases, the SR was decreased due to thermal softening of the workpiece. Surface roughness average values are shown in Table 6 which indicates the maximum optimal value 6.617 speed, 6.231 feed and DOC as 6.098. Table 7 shows the ANOVA, the maximum contribution of speed $59.083 \%$, feed $21.1455 \%$, DOC $8.967 \%$ and the interaction which also studied shows the value of $A B 2.664 \%, B C 1.576 \%$ AC $0.889 \%$ and error as $5.667 \%$.

\subsection{Effect of cutting force}

The outcome of the cutting force in the end milling process was the optimal level of average cutting force as shown in Fig. 7. The optimal values are shown in Table 8. The optimal level was A3-B3-C1 (speed $1000 \mathrm{rpm}$, feed $100 \mathrm{~mm} / \mathrm{min}$ and DOC $0.5 \mathrm{~mm}$ ). Table 9 shows the maximum contribution as feed rate $(50.373 \%)$ followed by the DOC, whereas at high cutting speed and feed, the 
Fig. 7 Optimal level of cutting force

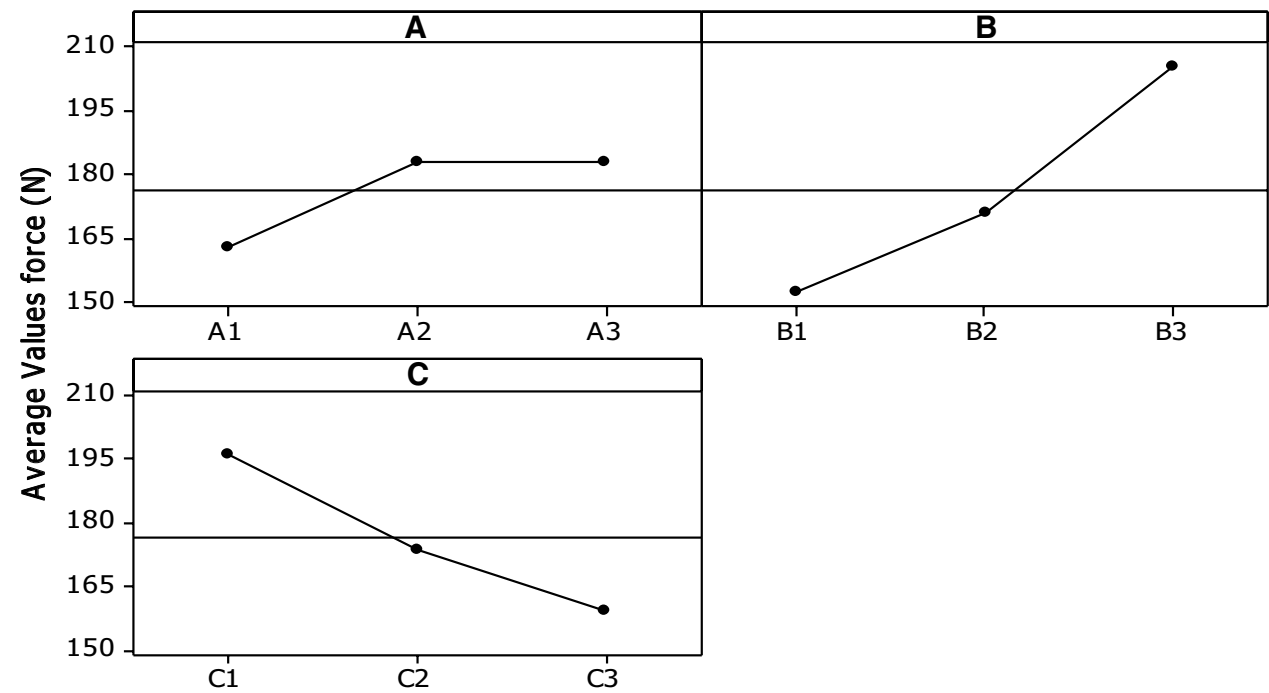

Table 8 Optimal values of cutting force

\begin{tabular}{llll}
\hline S. no & L1 & L2 & L3 \\
\hline 1 & 163.003 & 182.898 & $\mathbf{1 8 3 . 0 0 3}$ \\
2 & 152.213 & 171.162 & $\mathbf{2 0 5 . 5 3 0}$ \\
3 & $\mathbf{1 9 6 . 0 9 4}$ & 173.483 & 159.327 \\
\hline
\end{tabular}

Table 9 ANOVA for cutting force

\begin{tabular}{lcrrrl}
\hline Parameters & DOF & \multicolumn{1}{l}{ SS } & \multicolumn{1}{l}{ MSS } & \multicolumn{1}{l}{ Fcal } & \% contribution \\
\hline A & 2 & 2387.466 & 1193.733 & 9.669 & 9.146 \\
B & 2 & 13148.711 & 6574.355 & 53.250 & 50.373 \\
C & 2 & 6190.301 & 3095.150 & 25.070 & 23.715 \\
AB & 4 & 917.900 & 229.475 & 1.859 & 3.516 \\
BC & 4 & 1621.516 & 405.379 & 3.283 & 6.212 \\
AC & 4 & 849.083 & 212.271 & 1.719 & 3.253 \\
Error & 8 & 987.699 & 123.462 & & 3.784 \\
Total & 26 & 26102.676 & 1003.949 & & 100 \\
\hline
\end{tabular}

cutting force required was higher due to the effect of the coefficient of friction between the tool and the workpiece. At the same time, there was an increase in the DOC and there was a decrease in the cutting force due to softness of aluminum.

\subsection{Technique for order preference by similarity to ideal solution}

The effect of the Topsis in the end milling process of the optimal level of average cutting force is shown in Fig. 8. The average optimal values are shown in Table 10. The optimal level is A1-B1-C3 (speed $500 \mathrm{rpm}$, feed $40 \mathrm{~mm} /$ min and DOC $1 \mathrm{~mm}$ ). Table 11 illustrates the result of
ANOVA for the average values. It shows feed as the most influencing parameter, affecting the average values and the percentage of contributions. The feed contribution was observed as $43.537 \%$, speed as $25.664 \%$, DOC as $19.876 \%$ and interaction effect of speed, feed (AB) as $3.617 \%$, feed, DOC (BC) as $2.772 \%$, followed by speed, DOC (AC) as $1.691 \%$.

\subsection{Fuzzy logic}

The membership functions of input parameters are speed, feed and DOC with the output parameter as the Topsis value. The three input membership functions were: low $(L)$, medium $(M)$ and high $(H)$. The nine output membership functions are: EL (extremely low), VVL (very very low), VL (very low), L (low), M (medium), H (high), $\mathrm{VH}$ (very high), $\mathrm{VVH}$ (very very high), $\mathrm{EH}$ (extremely high). The input and output membership function values are shown in Table 12 and Fig. 9. The fuzzy rules are shown in "Appendix", and maximum fuzzy rule viewer is shown in Fig. 10. The surface viewers of speed and feed and the average value of FRG are shown in Fig. 11. It shows the increase in speed and feed followed by an increase in the average values (output). Figure 12 shows surface viewers of feed and DOC increases the FRG values also get increased (output). The yellow color represents the maximum, and red color shows the minimum of the output values.

Table 13 shows the optimal values of the fuzzy reasoning grade values at level-1, feed at level-1 and DOC at level-3 (A1-B1-C3). Figure 13 shows the optimal level as identified by $\mathrm{A} 1-\mathrm{B} 1-\mathrm{C} 3$. The figure shows that as speed and feed increase, the fuzzy average values are decreased; similarly, when feed increases the fuzzy average values also decrease. Table 14 shows the fuzzy values 
Fig. 8 Average levels of Topsis values

Table 10 Average of Topsis optimal values

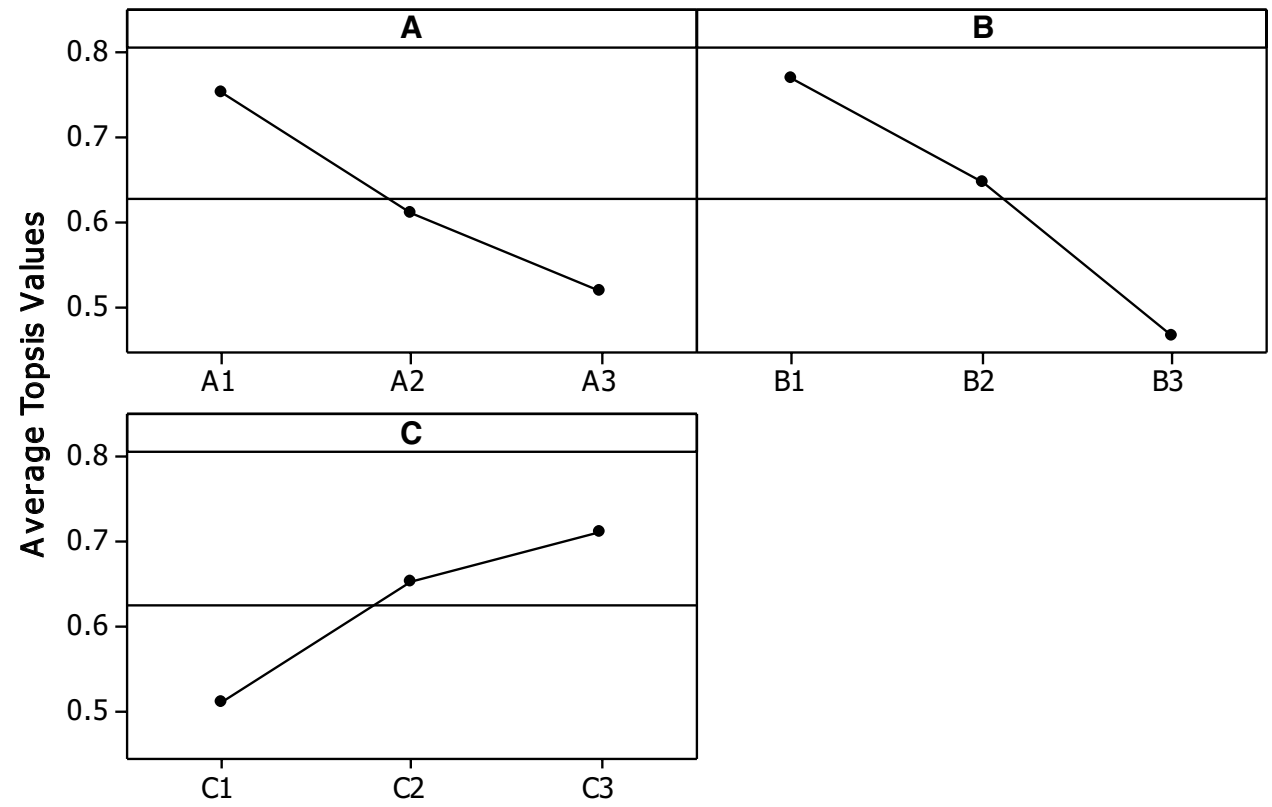

\begin{tabular}{llll}
\hline S. no & L1 & L2 & L3 \\
\hline 1 & $\mathbf{0 . 7 5 1}$ & 0.612 & 0.518 \\
2 & $\mathbf{0 . 7 7 0}$ & 0.647 & 0.596 \\
3 & 0.512 & 0.655 & $\mathbf{0 . 7 1 4}$ \\
\hline
\end{tabular}

Table 11 ANOVA for average Topsis values

\begin{tabular}{lcllll}
\hline Parameters & DOF & SS & MSS & $F$ & \% contribution \\
\hline A & 2 & 0.250 & 0.125 & 36.115 & 25.664 \\
B & 2 & 0.424 & 0.212 & 61.266 & 43.537 \\
C & 2 & 0.194 & 0.097 & 27.970 & 19.876 \\
AB & 4 & 0.035 & 0.009 & 2.545 & 3.617 \\
BC & 4 & 0.027 & 0.007 & 1.950 & 2.772 \\
AC & 4 & 0.016 & 0.004 & 1.190 & 1.691 \\
Error & 8 & 0.028 & 0.003 & & 2.842 \\
Total & 26 & 0.974 & 0.037 & & 100 \\
\hline
\end{tabular}

Table 12 Fuzzy input and output variables and ranges

\begin{tabular}{lllc}
\hline variables & Parameters & Fuzzy set & Range \\
\hline Input & Speed & L, M, H & $500-1000$ \\
& Feed & L, M, H & $40-100$ \\
& Depth of cut & L, M, H & $0.5-1$ \\
Output & Average Topsis values & EL, VVL, VL, L, M, & $0-1$ \\
& & H, VH, VVH, EH & \\
\hline
\end{tabular}

of feed contribution as $44.605 \%$ followed by speed as $24.333 \%$. The maximum interaction for speed and feed is $A B$ as $5.669 \%$.

\subsection{Response surface methodology (RSM)}

RSM explores the relationship between the machining parameter and the output response of the quadratic form. The two responses, adjusted $R^{2}(\mathrm{SR})$ value 0.9369 and the $R^{2}(F)$ value of force are 0.9083 . The $R^{2}$ values show the correlation with experimental values. The $3 D$ relation of surface roughness, resultant force and cutting parameter is shown in Figs. 14 and 15.

The performance values were close to the numerical values. The mathematical equations are given in Eqs. 4-7.

$$
\begin{aligned}
& \mathrm{SR}=2.39+0.17 * A+0.10 * B-0.064 * C \\
& -0.048 * A * B-0.014 * A * C-6.238 E-003 * B * C \\
& +7.415 E-003 * A^{2}-0.024 * B^{2}+0.036 * C^{2}
\end{aligned}
$$

Force $=13.48+0.33 * A+0.94 * B-0.69 * C$

$-0.20 * A * B+0.17 * A * C-0.32 * B * C$

$-0.45 * A^{2}-0.29 * B^{2}+0.20 * C^{2}$

Topsis $=0.76-0.056 * A-0.011 * B+4.047 E$

- $003 * C-0.020 * A * B-0.043 * A * C+0.044 * B * C$

$+0.020 * A 2+0.056 * B 2-0.046 * C 2$ 
Fig. 9 Range of membership function

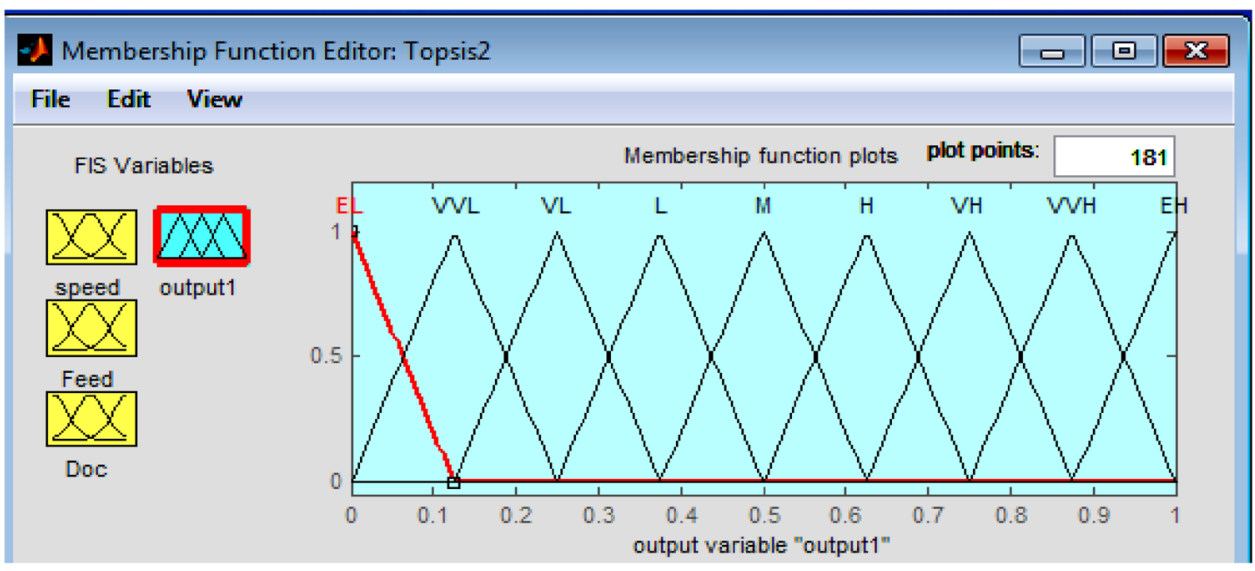

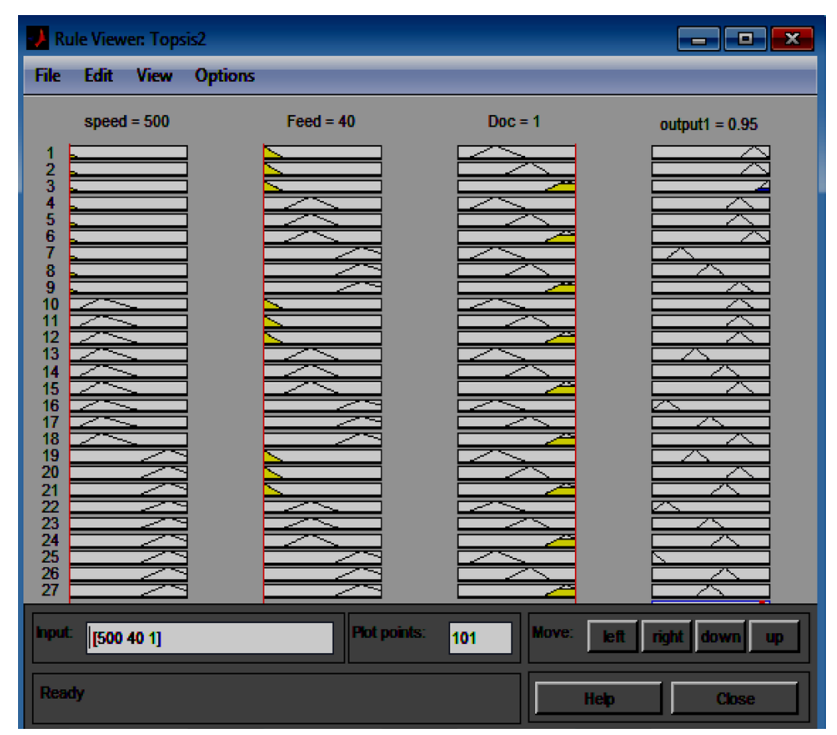

Fig. 10 Rule viewer of optimal value

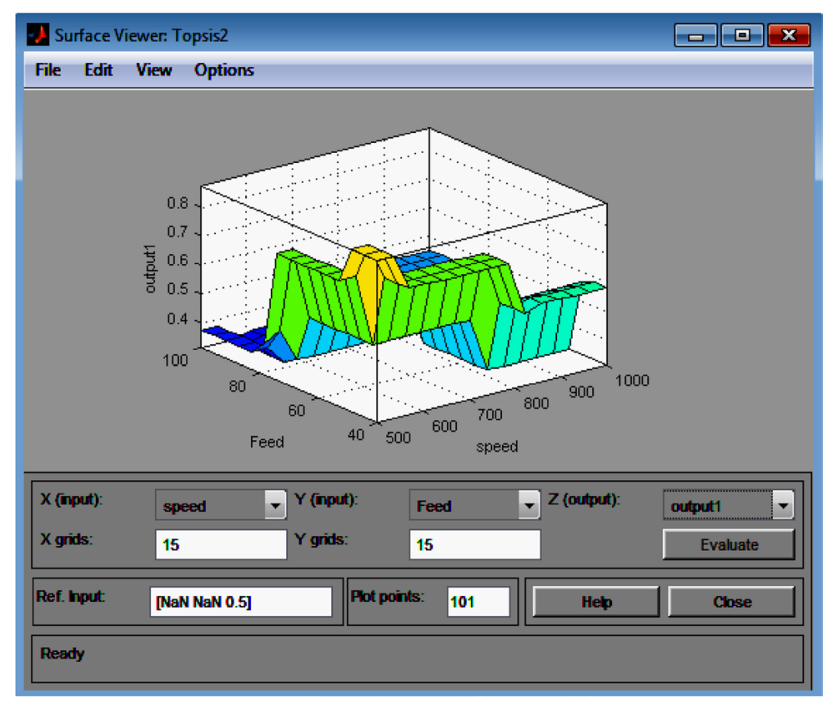

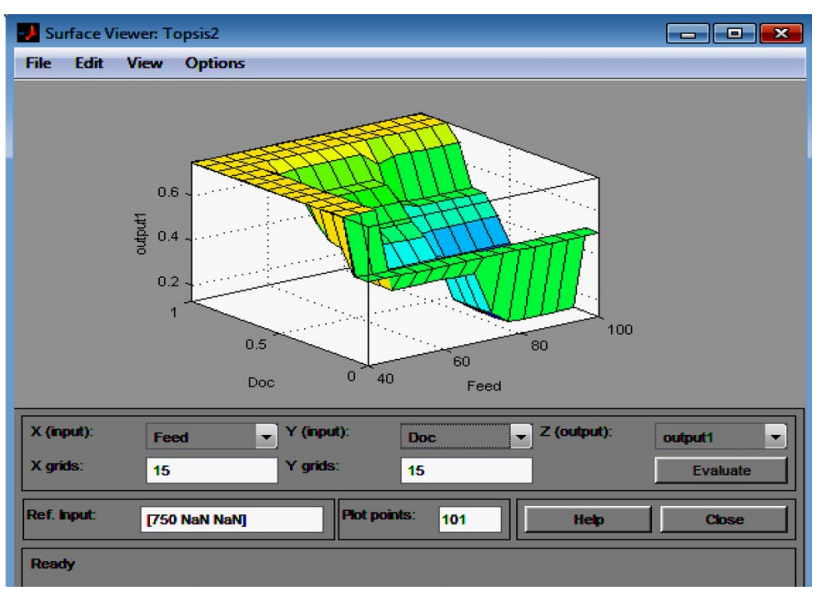

Fig. 12 Surface viewers of feed, DOC and output

Table 13 Optimal values of fuzzy

\begin{tabular}{llll}
\hline S. no & L1 & L2 & L3 \\
\hline 1 & $\mathbf{0 . 7 5 1}$ & 0.641 & 0.553 \\
2 & $\mathbf{0 . 7 7 8}$ & 0.658 & 0.596 \\
3 & 0.556 & 0.667 & $\mathbf{0 . 7 2 2}$ \\
\hline
\end{tabular}

$\mathrm{FRG}=0.79-0.058 * A-0.084 * B+0.055 * C$

$+0.026 * A * B-0.014 * A * C+0.027 * B * C$

$+0.018 * A 2+5.372 E-003 * B 2-0.021 * C 2$

The predicted values of $R_{\mathrm{a}}$ and $F_{\mathrm{z}}$ were acquired by using Eqs. 4 and 5, respectively, and compared with the measured values. In both the cases, the predicted values were observed to be statically similar to the actual values as appeared in Figs. 16 and 17. The wear is $0.012 \mu \mathrm{m}$, and the image of scanning electron microscope of tool wear is shown in Fig. 18a. The optimal machined surface

Fig. 11 Surface viewers of speed, feed and output 
Fig. 13 Optimal level of fuzzy value

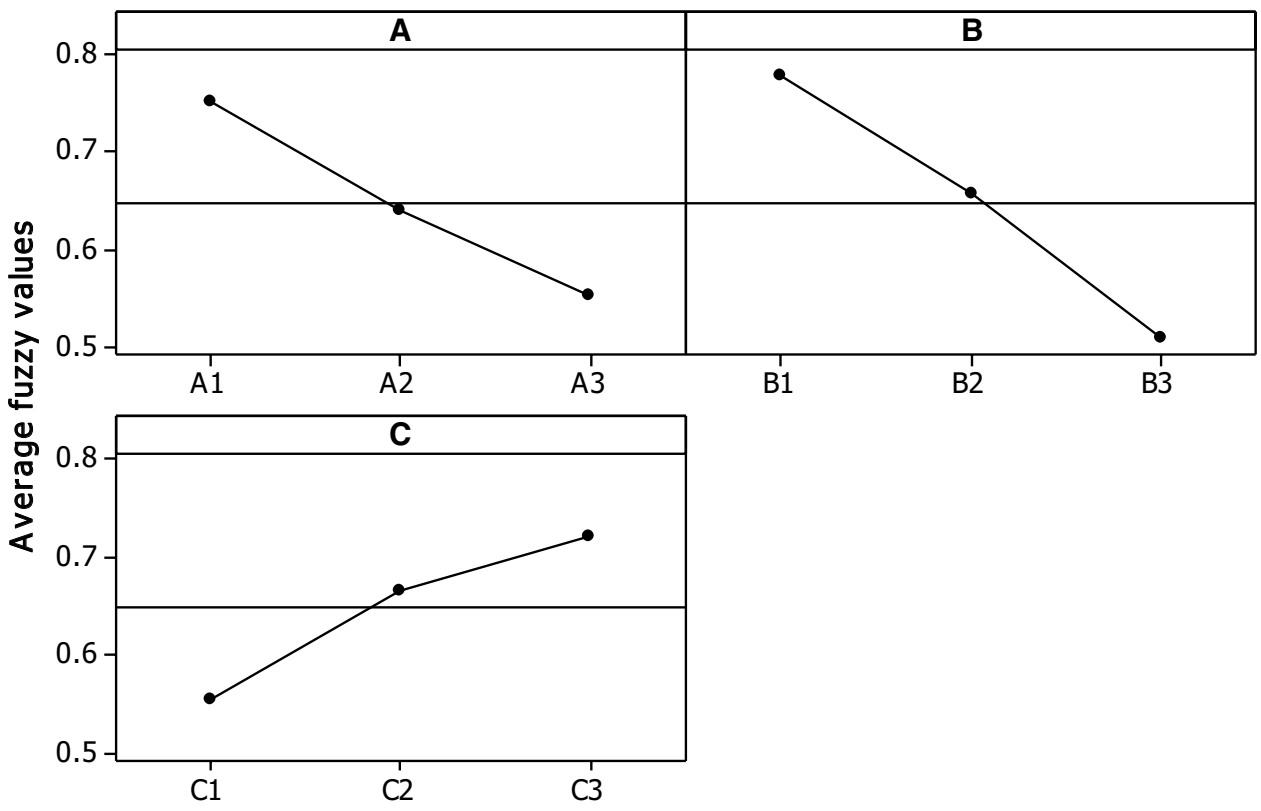

Table 14 ANOVA for fuzzy logic

\begin{tabular}{lcllll}
\hline Parameters & DOF & SS & MSS & F & \% contribution \\
\hline A & 2 & 0.178 & 0.089 & 27.544 & 24.333 \\
B & 2 & 0.327 & 0.163 & 50.492 & 44.605 \\
C & 2 & 0.129 & 0.065 & 19.984 & 17.654 \\
AB & 4 & 0.042 & 0.010 & 3.208 & 5.669 \\
BC & 4 & 0.016 & 0.004 & 1.270 & 2.244 \\
AC & 4 & 0.014 & 0.004 & 1.110 & 1.961 \\
ERROR & 8 & 0.026 & 0.003 & & 3.534 \\
TOTAL & 26 & 0.732 & 0.028 & & 100 \\
\hline
\end{tabular}

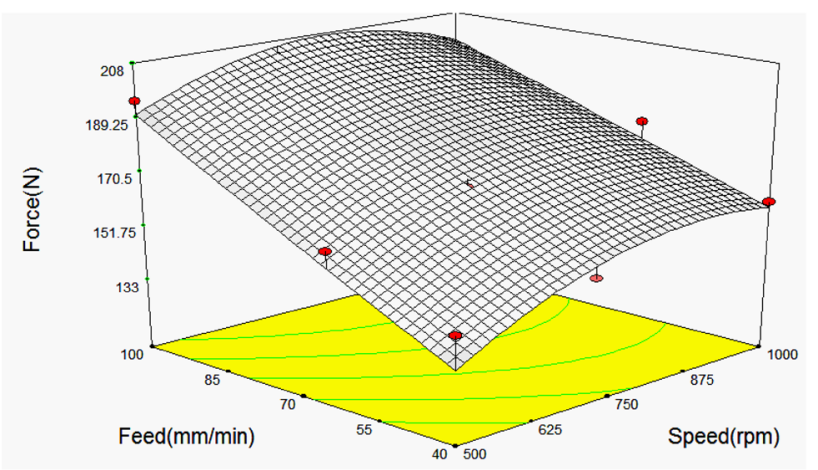

Fig. 153 D relation of speed, feed and cutting force

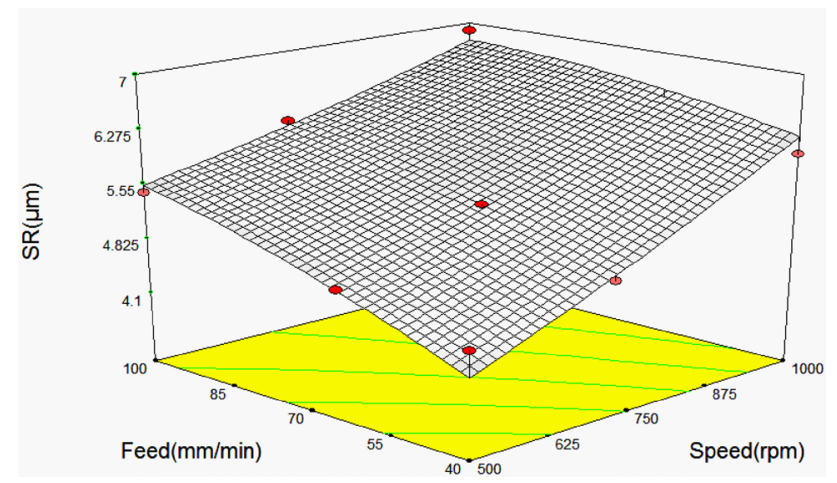

Fig. 143 D relation of speed, feed and SR

(A1-B1-C3) is shown in Fig. 18b. The surface demonstrates a good finish, and great appearance is distinguished from other machining process.

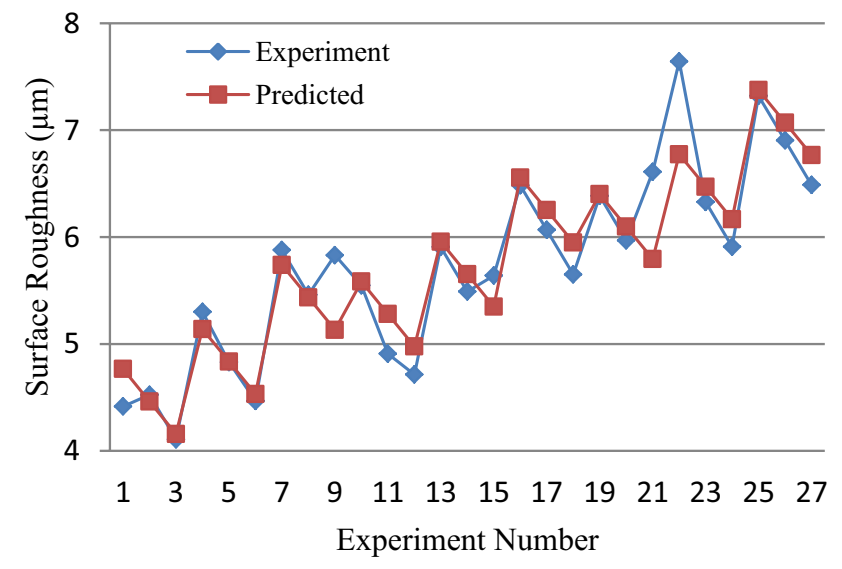

Fig. 16 Comparison of experimental and predicted values (SR) 


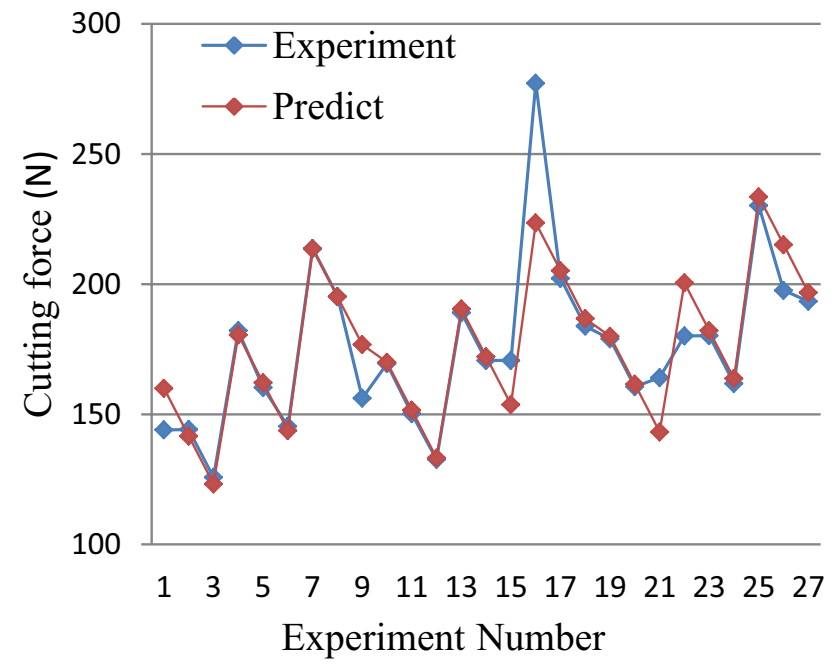

Fig. 17 Comparison of experimental and predicted values (CF)

\section{Confirmation experiment}

The confirmation experiment was the ultimate step to substantiate the advance in performance characteristics at the optimal level of machining parameters. An experiment was conducted based on the optimal condition. The predicted Topsis with fuzzy reasoning grade was calculated using Eq. (8).

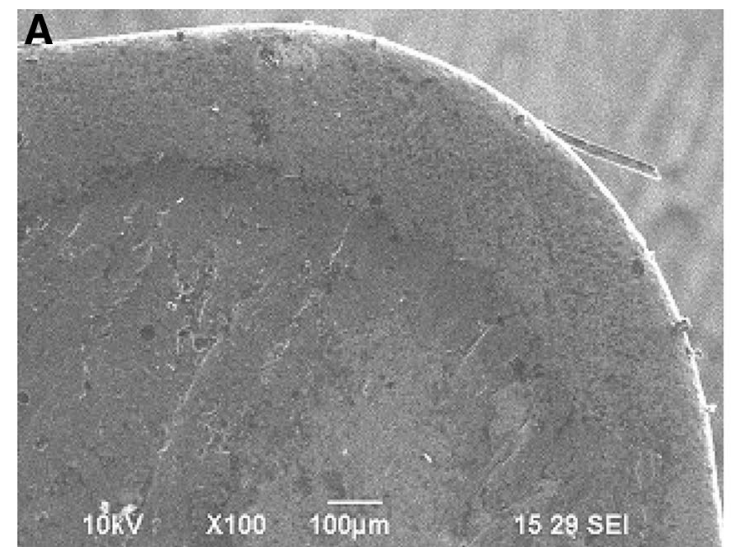

$\eta_{\text {Predicted }}=\eta_{0}+\sum_{i=1}^{n}\left(\eta_{m}-\eta_{0}\right)$

where $\eta_{0}$ is the fuzzy reasoning grade mean, $\eta_{m}$-mean of fuzzy reasoning grade at the optimal level of $A, B$ and $C$, and $n$-number of significant parameters $(n=3)$. The confirmation results are shown in Table 15 and reveal that the surface roughness values decrease from 4.416 to $4.108 \mu \mathrm{m}$ and force from 144 to $125.766 \mathrm{~N}$. The improvement in technique for order preference by similarity to ideal solution is $12.36 \%$, and a fuzzy logic value is $6.98 \%$ from the experimental value to the initial condition. A higher Topsis and $\mathrm{Fl}$ in an optimal setting confirm the enhancement in multiperformance characteristics. There was an improvement within the tool life of the insert beneath the optimum conditions.

\section{Conclusions}

End milling operations were conducted with tungsten carbide insert on aluminum metal matrix composite, and process parameters were analyzed regarding $R_{\mathrm{a}}$ and $F_{z}$ through variation in the speed, feed and DOC. Multi-objective optimization was performed using Topsis and Fl. From the response, the machining conditions

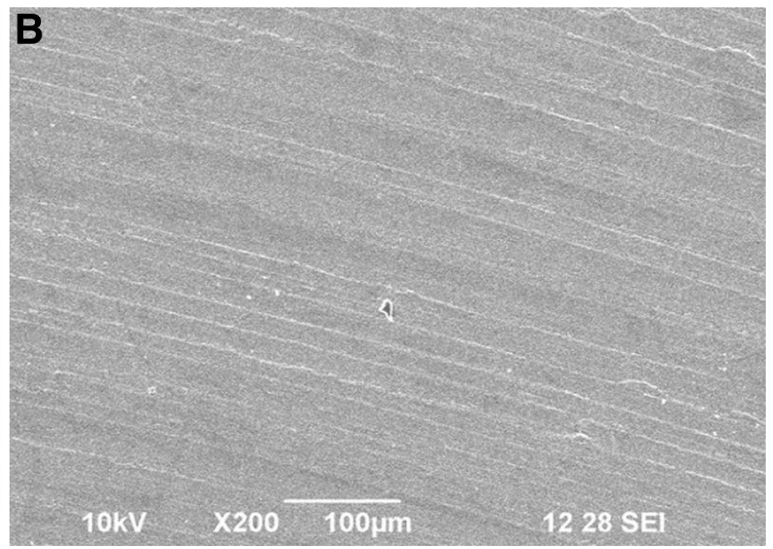

Fig. 18 a Tool wear (0.012 $\mu \mathrm{m})$. b SEM image of milled surface (A1-B1-C3)

Table 15 Confirmation test results

\begin{tabular}{lllccc}
\hline Process & $\begin{array}{l}\text { Initial (A1- } \\
\text { B1-C1) }\end{array}$ & $\begin{array}{l}\text { Predicted (A1- } \\
\text { B1-C3) }\end{array}$ & Experimental & Variation & \% improvement \\
\hline SR $(\mu \mathrm{m})$ & 4.416 & - & 4.108 & 0.308 & 6.97 \\
Force $(N)$ & 144 & - & 125.766 & 18.234 & 12.66 \\
Topsis & 0.890 & 0.981 & 1.000 & 0.11 & 12.36 \\
Fuzzy & 0.888 & 0.955 & 0.950 & 0.062 & 6.98 \\
Improvement in Topsis is 12.36\% & & & \\
\hline
\end{tabular}


were obtained. From the analysis, following points are concluded.

- The mathematical study of the influence of individual parameters demonstrates that speed $(59.083 \%)$ is the important parameter which influences the $S R$, where the feed $(50.373 \%)$ influences the cutting force.

- The ANOVA demonstrated the most influence factor for both Topsis and Fl. This analysis indicates that the speed and feed rate are the dominant factors for surface roughness and cutting force.

- Topsis is used to reveal the effect of parameters influencing both $R_{\mathrm{a}}$ and $F_{\mathrm{z}}$. Feed is found as the transcendent parameter that influences both $R_{\mathrm{a}}$ and $F_{\mathrm{z}}$. Topsis is used to identify the optimum machining parameters such as cutting speed of $500 \mathrm{rpm}$, the feed rate of $40 \mathrm{~mm} / \mathrm{min}$ and DOC of $1 \mathrm{~mm}$ from the third experiment.

- The relative closeness values of fuzzy logic are used to find the optimal levels in the experiments. The most extreme fuzzy reasoning grade is identified in the third experiment (A1-B1-C3). The optimal level found in the Topsis and $\mathrm{Fl}$ is the same.

- According to Topsis and Fl, the smallest values of speed, feed and depth of cut lead to $R_{a}$ and $F_{z}$ values as shown in Table 4.

- The response surface methodology is effectively used to create the numerical model between machining parameters.

- From the quadratic polynomial model, the obtained correlation coefficient $R^{2}$ values are $93.69 \%$ and $90.83 \%$. The value indicates that the generated model can be used to predict $R_{\mathrm{a}}$ and $F_{\mathrm{z}}$ in milling operation.

- The total number of experiments in milling operations is reduced by using Topsis and FI for determining the optimum cutting conditions. The results acquired in this research would be useful in manufacturing sectors.

The methodology offered experimentally and statically during this study is often viewed as an applicable method for the improvement in milling processes.

\section{Compliance with ethical standards}

Conflict of interest The authors declare that they have no conflict of interest.

Open Access This article is distributed under the terms of the Creative Commons Attribution 4.0 International License (http://creativeco mmons.org/licenses/by/4.0/), which permits unrestricted use, distribution, and reproduction in any medium, provided you give appropriate credit to the original author(s) and the source, provide a link to the Creative Commons license, and indicate if changes were made.

\section{Appendix: Fuzzy rules}

if (Speed is $\mathrm{L}$ ) and (Feed is $\mathrm{L}$ ) and (DOC is $\mathrm{L}$ ) Then (output is $\mathrm{VVH})$

if (Speed is $\mathrm{L}$ ) and (Feed is M) and (DOC is M) Then (output is VVH)

if (Speed is $\mathrm{L}$ ) and (Feed is $\mathrm{H}$ ) and (DOC is $\mathrm{H}$ ) Then (output is EH)

if (Speed is $\mathrm{L}$ ) and (Feed is $\mathrm{L}$ ) and (DOC is $\mathrm{L}$ ) Then (output is $\mathrm{VH}$ )

if (Speed is $\mathrm{L}$ ) and (Feed is M) and (DOC is M) Then (output is $\mathrm{VH}$ )

if (Speed is $\mathrm{L}$ ) and (Feed is $\mathrm{H}$ ) and (DOC is $\mathrm{H}$ ) Then (output is $\mathrm{VVH}$ )

if (Speed is $\mathrm{L}$ ) and (Feed is $\mathrm{L}$ ) and (DOC is $\mathrm{L}$ ) Then (output is VL)

if (Speed is $\mathrm{L}$ ) and (Feed is $\mathrm{M}$ ) and (DOC is M) Then (output is $M)$

if (Speed is $\mathrm{L}$ ) and (Feed is $\mathrm{H}$ ) and ( $\mathrm{DOC}$ is $\mathrm{H}$ ) Then (output is $\mathrm{VH}$ )

if (Speed is $\mathrm{M}$ ) and (Feed is $\mathrm{L}$ ) and (DOC is $\mathrm{L}$ ) Then (output is $\mathrm{VH}$ )

if (Speed is M) and (Feed is M) and (DOC is M) Then (output is $\mathrm{VH}$ )

if (Speed is M) and (Feed is $\mathrm{H}$ ) and (DOC is $\mathrm{H}$ ) Then (output is $\mathrm{VH}$ )

if (Speed is $\mathrm{M}$ ) and (Feed is $\mathrm{L}$ ) and (DOC is $\mathrm{L}$ ) Then (output is $L$ )

if (Speed is M) and (Feed is M) and (DOC is M) Then (output is $\mathrm{H}$ )

if (Speed is M) and (Feed is H) and (DOC is H) Then (output is $\mathrm{VH}$ )

if (Speed is M) and (Feed is $\mathrm{L}$ ) and (DOC is L) Then (output is $\mathrm{VVL}$ )

if (Speed is M) and (Feed is M) and (DOC is M) Then (output is M)

if ( $\mathrm{Speed}$ is $\mathrm{M}$ ) and (Feed is $\mathrm{H}$ ) and (DOC is H) Then (output is $\mathrm{VH}$ )

if (Speed is $\mathrm{H}$ ) and (Feed is $\mathrm{L}$ ) and (DOC is $\mathrm{L}$ ) Then (output is $\mathrm{L}$ )

if (Speed is $\mathrm{H}$ ) and (Feed is $\mathrm{M}$ ) and (DOC is M) Then (output is $\mathrm{VH}$ )

if $($ Speed is $\mathrm{H})$ and (Feed is $\mathrm{H}$ ) and (DOC is $\mathrm{H}$ ) Then (output is $\mathrm{H}$ )

if (Speed is $\mathrm{H}$ ) and (Feed is $\mathrm{L}$ ) and (DOC is $\mathrm{L}$ ) Then (output is $\mathrm{VVL}$ )

if ( $\mathrm{Speed}$ is $\mathrm{H}$ ) and (Feed is $\mathrm{M}$ ) and (DOC is M) Then (output is $M)$

if (Speed is $\mathrm{H}$ ) and (Feed is $\mathrm{H}$ ) and (DOC is $\mathrm{H}$ ) Then (output is $\mathrm{H}$ )

if (Speed is $\mathrm{H}$ ) and (Feed is $\mathrm{L}$ ) and (DOC is $\mathrm{L}$ ) Then (output is EL) 
if (Speed is $\mathrm{H}$ ) and (Feed is M) and (DOC is M) Then (output is $\mathrm{H}$ )

if (Speed is $\mathrm{H}$ ) and (Feed is $\mathrm{H}$ ) and (DOC is $\mathrm{H}$ ) Then (output is $M)$

\section{References}

1. Kilickap E, Cakir O, Aksoy M, Inan A (2005) Study of tool wear and surface roughness in machining of homogenized $\mathrm{SiC}_{\mathrm{p}}$ reinforced aluminum metal matrix composite. J Mater Process Technol 165:862-867

2. Mohan B, Rajadurai A, Satyanarayana KG (2004) Electric discharge machining of $\mathrm{Al} / \mathrm{SiCp}$ metal matrix composites using rotary turbo electrode. J Mater Process Technol 153:978-985

3. Yoon K (1987) A reconciliation among discrete compromise situations. J Oper Res Soc 38:277-286

4. Vinodh S, Prasanna M, Prakash NH (2014) Integrated fuzzy AHP-TOPSIS for selecting the best plastic recycling method: a case study. Appl Math Model 38(19):4662-4672

5. Nayak BB, Mahapatra SS (2013) Multi-response optimization of WEDM process parameters using the AHP and TOPSIS method. Int J Theor Appl Res Mech Eng 2(3):109-215

6. Dewangan S, Gangopadhyay S, Biswas CK (2015) Study of surface integrity and dimensional accuracy in EDM using fuzzy topsis and sensitivity analysis. Measurement 63:364-376

7. Awasthi S, Chauhan SS, Omrani H, Panahi A (2011) A hybrid approach based on SERVQUAL and fuzzy TOPSIS for evaluating transportation service quality. Comput Ind Eng 61:637-646

8. Torfi F, Farahani RZ, Rezapour S (2010) Fuzzy AHP to determine the relative weights of evaluation criteria and fuzzy topsis to rank the alternatives. J Appl Soft Comput 10(2):520-528

9. Onut S, Kara SS, Tugba E (2008) A hybrid fuzzy MCDM approach to machine tool selection. J Intell Manuf 19:443-453

10. Yurdalul S, IC YT (2009) Analysis of the benefit generated by using fuzzy members in a topsis model developed for machine tool selection problems. J Mater Process Technol 209:310-317

11. Sidhu SS, Batish A, Kumar S (2014) Study of surface properties in particulate- reinforced metal matrix composites (MMCs) using powder-mixed electrical discharge machining (EDM). Mater Manuf Process 29:46-52

12. Gadakh VS (2012) Parametric optimization of wire electric discharge machining using Topsis method. Adv Prod Eng Manag 3:157-164

13. Yurdakul N, Cogun C (2003) Development of a multi-attribute selection procedure for nontraditional machining processes. Part B J Eng Manuf 217(7):993-1009

14. Temucin T, Tozan H, Valicek J, Harnicarova M (2013) A fuzzy based decision support model for non-traditional machining process selection. Tech Gaz 20(5):787-793

15. Shivakoti I, Pradhan BB, Diyaley S, Ghadai RK, Kalita K (2017) Fuzzy Topsis ased selection of laser beam micro-marking process parameters. Arab J Sci Eng 42:4825-4831

16. Kumar D, Payal S, Beri N (2017) Parameters optimized specifying for EDM with PM/conventional electrodes on $\mathrm{M} 2$ tool steel using Taguchi and Topsis. Ind J Sci Technol 10(22):1-8

17. Sidhu SS, Batish A, Kumar S (2014) Study of surface properties in particulate-reinforced metal matrix composites (MMCS) using powder-mixed electrical discharge machining (EDM). Mater Manuf Process 29:46-52. https://doi.org/10.1080/10426 914.2013.852211
18. Shunmugesh K, Panneerselvam K (2017) Optimization of machining process parameters in drilling of CFRP using multiobjective Taguchi technique, TOPSIS and RSA techniques. Polym Polym Compos 25(3):185-192

19. Gok A (2015) A new approach to minimization of the surface roughness and cutting force via fuzzy Topsis, multi-objective grey design and RSA. Measurement 70:100-109

20. Tamiloli N, Venkatesan J, Vijaya Ramanath B (2016) A greyfuzzy modeling for evaluating surface roughness and material removal rate of coated end milling insert. Measurement 84:68-82

21. Sidhu SS, Yazdani M (2017) Comparative analysis of MCDM techniques for EDM of SiC/A359 composite. Arab J Sci Eng 8:8-9. https://doi.org/10.1007/s13369-017-2726-5

22. Ashvin MJ, Nanavati J (2013) Optimisation of machining parameters for turning operations based on response surface methodology. Measurement 46(4):1521-1529

23. Sidhu SS, Batish A, Kumar S (2014) ED machining of particulate reinforced MMCs. Eng Technol Int J Mech Ind Sci Eng 8(3):1-7

24. Roy T, Dutta RK (2019) Integrated fuzzy AHP and fuzzy topsis methods for multi-objective optimization of electro discharge machining process. Soft Comput 23(13):5053-5063

25. Pattnaik SK, Mahapatra KD, Priyadarshini M (2015) Multi objective optimization of EDM process parameters using fuzzy topsis method. In: IEEE Spons 2D international conference on innovations in information embedded and communications systems (ICIIECS), pp 1-5. https://doi.org/10.1109/ICIIECS.2015.7192926

26. Rupajati P, Soepangkat BOP, Pramujati B, Agustin HCK (2014) Optimization of recast layer thickness and surface roughness in the wire EDM process of AISI $\mathrm{H} 13$ tool steel using Taguchi and fuzzy logic. Appl Mech Mater 493:529-534

27. Dincer SE (2011) Multi-criteria analysis of economic activity for European Union member states and candidate countries Topsis and WSA applications. Eur J Soc Sci 21(4):563-572

28. Iravani Z, Lotfi FH, Namin MA (2009) An algorithm for the calculation of progress or regress via Topsis and Malmquist productivity index. Appl Math Sci 3(52):2553-2562

29. Salehi M, Moghaddam RJ (2008) Project selection by using a fuzzy topsis technique. world academic of science. Eng Technol 40:85-90

30. Fan CK, Cheng SW (2009) Using analytic hierarchy process method and technique for techniques order preference by similarity to ideal solution to evaluate curriculum in the department of risk management and insurance. J Soc Sci 19(1):1-8

31. Nilashi M, Bagherifard K, Ibrahim O, Janahmadi N, Alizadeh $\mathrm{H}$ (2012) Multi-criteria approach to the evaluation of malaysian government portal. J Theor Appl Inf Technol 40(2):194-201

32. Yasir M, Ginta TL, Ariwahjoedi B, Alkali AU, Danish M (2016) Effect of cutting speed and feed rate on surface roughness of AISI 3161 SS using end-milling. ARPN J Eng AppI Sci 11(4):2496-2500

33. Camuscu N (2006) Effect of cutting speed on the performance of $\mathrm{Al}_{2} \mathrm{O}_{3}$ based ceramic tools in turning nodular cast iron. Mater Des 27:997-1006

34. Morehead MD, Huang Y, Luo J (2007) Chip morphology characterization and modeling in machining hardened 52100 steels. Mach Sci Technol 11:335-354

35. Das SR, Dhupal D, Kumar A (2015) Experimental investigation into machinability of hardened AISI 4140 steel using TiN coated ceramic tool. Measurement 62:108-126

Publisher's Note Springer Nature remains neutral with regard to jurisdictional claims in published maps and institutional affiliations. 